\title{
Paediatric Nephrology in Africa
}

\author{
Christopher I. Esezobor ${ }^{1,2} \cdot$ Adebimpe E. Alakaloko $^{2} \cdot$ Bashir Admani $^{3} \cdot$ Rashid Ellidir $^{4,5} \cdot$ Peter Nourse $^{6}$. \\ Mignon I. McCulloch ${ }^{6}$
}

Accepted: 22 September 2021 / Published online: 25 October 2021

(C) The Author(s), under exclusive licence to Springer Science+Business Media, LLC, part of Springer Nature 2021

\begin{abstract}
Purpose of Review We highlight the unique facets of paediatric nephrology in Africa in terms of the spectrum of kidney diseases, available diagnostic and treatment modalities, kidney healthcare financing options, paediatric nephrology manpower and the contribution of geography and demographics.

Recent Findings Paediatric acute kidney injury in Africa is now commonly due to sepsis rather than gastroenteritis. Steroidsensitive form of nephrotic syndrome is far more common than was two decades ago.

Summary The hot arid climate in North Africa and the tropical climate in most of sub-Saharan Africa, and the high rate of consanguinity, sickle cell disease and HIV drive the spectrum of paediatric kidney diseases in the continent. Kidney diseases are often precipitated by infectious triggers associated with poor living conditions and little access to medical care thus resulting in late presentation and often end-stage kidney disease. Although accessibility to kidney care has improved in the continent due to training opportunities provided by international professional organisations, most children still face significant barriers to kidney care because they live in rural areas, governments spend the least on healthcare and the continent has the least density of healthcare practitioners and nephrology trainees.
\end{abstract}

Keywords Acute kidney injury $\cdot \mathrm{HIV} \cdot$ Kidney transplantation $\cdot$ Malaria $\cdot$ Nephrotic syndrome $\cdot$ Sickle cell disease

\section{Introduction}

Christopher I. Esezobor

esezobor@gmail.com

1 Department of Paediatrics, Faculty of Clinical Sciences, College of Medicine, University of Lagos, Idi-Araba, Lagos State, Nigeria

2 Department of Paediatrics, Lagos University Teaching Hospital, Idi-Araba, Lagos State, Nigeria

3 Department of Paediatrics and Child Health, College of Health Sciences, University of Nairobi, Nairobi, Kenya

4 Department of Pediatric Nephrology, Noura Children Center for Kidney Disease and Transplantation, Soba University Hospital, Khartoum, Sudan

5 Multi Organ Transplant Centre (MOTC), Paediatric Nephrology Department, King Fahad Specialist Hospital, Dammam, Saudi Arabia

6 Depatment of Pediatric Nephrology, Red Cross War Memorial Children's Hospital, University of Cape Town, Cape Town, South Africa
Africa is the second largest continent defined by land mass after Asia. The continent comprises 54 countries conveniently divided into five regions, namely Northern Africa, Western Africa, Eastern Africa, Middle/Central Africa, and Southern Africa. Geographically, most of the continent lies below the Sahara Desert and experience a tropical or temperate climate. The countries north of the Saharan desert face a hot arid climate that promotes stone formation in the urinary tract. The tropical climate in most of the countries in subSaharan Africa (SSA) is conducive for bacterial infections, tuberculosis and vector-borne diseases such as malaria. The continent is home to $17 \%$ of the world's population of 7.8 billion people and it is the youngest continent with a median age of 19.7 years; $40 \%$ of the continent's population is under 14 years $[1,2,3]$. In contrast, the median age of the world is 30.9 years. About half of the population of the continent reside in rural areas which is characterised by a high burden of infectious diseases and limited access to social amenities and healthcare with traditional remedies often the first remedy for any illness. 
Africa is the poorest continent with a GDP per capita that is one-sixth of the global average [2,3]. Of the 20 countries in the world with the lowest GDP per capita, 18 are in Africa [3]. Only six African countries (South Africa, Namibia, Botswana, Gabon, Equatorial Guinea and Libya) are rated as upper middle-income countries and none as high-income country (HIC) by the World Bank [4].

Its relatively young population, high fertility rate, unique climate, and high poverty rate act in concert to shape the practice of paediatric nephrology in the continent.

\section{Spectrum of Kidney Diseases in Children in the Continent}

Acute kidney injury (AKI) and nephrotic syndrome are the most reported paediatric kidney diseases in Africa (Table 1) [5-7, 8•]. The dramatic presentations of nephrotic syndrome and severe acute kidney injury reduce the likelihood of missed diagnoses. In contrast, the prevalence of chronic kidney disease and congenital anomalies of the kidneys and urinary tract remains low due to the absence of screening or antenatal ultrasound investigation and thus often an underestimation. Apart from North Africa and the Republic of South Africa, genetic kidney diseases in children are infrequently reported in the continent due to cost and unavailability of the tests $[9,10]$. In North Africa, consanguinity contributes to the high prevalence of diseases such as sickle cell anaemia, hyperoxaluria and nephronophthisis while the hot arid climate coupled with high consanguinity promotes a high burden of urolithiasis in children [5, 11]. In most parts of subSaharan Africa, the high burden of malaria is reflected in its frequent finding in children with AKI $[12,13 \bullet \bullet]$. About $40 \%$ of the 409,000 deaths from malaria in 2019 occurred in three African countries, namely Nigeria, Democratic Republic of
Congo and Tanzania [14•]. Two recent studies that used the Kidney Disease: Improving Global Outcomes (KDIGO) consensus definition of AKI documented that $45.5-59 \%$ of children with severe malaria in two African countries developed AKI $[15,16 \bullet \bullet]$.

Although the spectrum of kidney diseases in children in the continent may be similar to those of children in other regions of the world, there are unique features that bear material impact on the course of kidney diseases in the continent. Acute kidney injury in Africa is frequently community-acquired and due to sepsis, malaria, perinatal asphyxia and, less commonly to, gastroenteritis due to unsafe water and sanitation $[12,13 \bullet \bullet, 17-20]$. Acute kidney injury due to perinatal asphyxia is partly driven by the high out-of-facility delivery of newborns that is prevalent in the continent [21]. Late presentation to medical facilities colours the presentation and course of many diseases in Africa [22, 23]. It is not unusual for children with nephrotic syndrome to present to healthcare with fluid oozing out from the skin. In addition, there are many children with congenital anomalies of the kidneys and urinary tract (CAKUT), such as posterior urethral valve (PUV), who present for the first time after the age of five years or in adolescence with little residual kidney function [24•]. Not uncommonly, despite the increased availability of ultrasonography, many children with CAKUT are not diagnosed before birth $[25,26]$. This underlines a need for manpower training but may also reflect the grim situation where about $35 \%$ of births in the continent occur outside health facilities [21]. In practice, the paediatric nephrologist in the continent is frequently caring for children with common kidney diseases who have the most severe forms with little residual kidney function.

Secondary causes of glomerular diseases are relatively more common than in high-income countries. The continent is home to the largest population of people living with
Table 1 Pattern of childhood kidney diseases in some African countries

\begin{tabular}{lllll}
\hline Study ID & Ali [5] & Ladapo [7] & Antwi [6] & Obiagwu [8•] \\
\hline Country & Sudan & Nigeria & Ghana & Nigeria \\
Region & North Africa & West Africa & West Africa & West Africa \\
Publication date & 2012 & 2014 & 2015 & 2019 \\
Year of study & $2000-2004$ & $2008-2011$ & $2010-2012$ & $2015-2017$ \\
Number of children & 200 & 320 & 664 & 244 \\
Kidney diseases (\%) & & & & \\
Acute kidney injury & 6.0 & 20 & 31 & 13.9 \\
Nephrotic syndrome & 17.0 & 22.8 & 27.3 & 33.6 \\
Acute glomerulonephritis & 12.0 & 10 & 11.9 & 25.8 \\
Chronic kidney disease & 4.0 & 4.2 & 13.0 & 13.9 \\
CAKUT & 10.0 & 17.5 & 7.4 & 7.8 \\
Stones & 15.5 & - & - & 2.9 \\
Urinary tract infection & 30.0 & 3.1 & 3.0 & 2.0 \\
\hline
\end{tabular}

$C A K U T$, congenital anomalies of the kidneys and urinary tract 
HIV. As a result, HIV-related kidney diseases are frequently reported in both children and adults [27, 28•]. Furthermore, the high prevalence of sickle cell disease in the malariaendemic region of Africa (most of Western, Middle and Eastern Africa) drives the burden of secondary glomerular disease [27, 29]. Again, in contrast to HIC, childhood nephrotic syndrome in Africa was historically likely to be steroid resistant. However, two large recent studies among Black children in Côte d'Ivoire and Nigeria reported a steroid sensitivity rate more than $80 \%$ similar to rates observed in European and Asian children with nephrotic syndrome [30••, 31]. Furthermore, a recent systematic review documented increasing rates of steroid-sensitive form of childhood nephrotic syndrome compared with resistant form [32]. Acute glomerulonephritis due to streptococcal infection remains a commonly reported kidney disease in children in Africa (Table 1), but more children with glomerular diseases due to systemic lupus erythematosus are increasingly being recognised [33, 34].

The absence of a comprehensive paediatric renal registry for the continent (there is an active renal registry in South Africa) means the true burden of end-stage kidney disease (ESKD) in children is largely unknown and infrequently reported. Hence, there are few reports of the burden of ESKD in children in Africa. The scant data available suggest that the prevalence of paediatric ESKD is much lower in Africa than in North America and Europe. A recent single-centre study in Nigeria put the incidence of ESKD among children $<15$ years at 4 per million at risk population [22]. Overall, in contrast to CAKUT as the leading cause of ESKD in children in Europe and North America, glomerular diseases are the frequently reported causes of paediatric ESKD in the continent (see Table 2) [22, 35, 36]. It does appear that in regions of Africa where non-Black children predominate, CAKUT is the most common cause of chronic kidney disease (CKD) and the converse is the case in regions where Blacks predominate. For example, in Egypt and Cape Town, South Africa, CAKUT is the leading cause of CKD, whereas, in Nigeria, KwaZulu-Natal, South Africa, and among Blacks in Johannesburg, South Africa, glomerular diseases were the most frequent causes of CKD [22, 36-39].

\section{Modalities of Treating Kidney Diseases}

Availability of diagnostic and treatment modalities for kidney diseases in Africa is among the poorest in the world. The Global Kidney Health Atlas 2019, which detailed the 2018 survey of the ISN, documented that only 4 and $10 \%$ of patients with ESKD in low-income countries (LIC) and low middle-income countries (LMIC), respectively, received kidney replacement therapy compared with $60 \%$ in Western Europe [40••]. Furthermore, most of the countries with the least chronic haemodialysis (HD) and peritoneal dialysis (PD) centre densities are in Africa. In most countries in Africa, the survey estimated the chronic HD centre density at $<1.2$ per million population ( $\mathrm{pmp}$ ). In Chad and Mozambique, for example, the density was $0.1 \mathrm{pmp}$. In addition, chronic PD was only available in 15 of the 42 African countries surveyed. In the continent, access of children to kidney care lags those for adults and is frequently inferior to adult services. The survey confirmed large disparities in ESKD care and access to KRT between children and adults within the same country. The disparity is more marked in LIC and LMIC to which about $90 \%$ of the countries in Africa belong. In LIC, the survey respondents reported disparity in ESKD care and KRT access in $61 \%$ and $57 \%$ of the countries, respectively, compared to $19 \%$ and $9 \%$, respectively, in HIC. Some of the disparities are evident in the non-availability of size-compatible consumables for urodynamic investigations, catheters for haemodialysis and peritoneal dialysis and blood lines for haemodialysis [41]. Not infrequently, adult-sized

Table 2 Major causes of chronic kidney diseases in African children

\begin{tabular}{|c|c|c|c|c|c|c|}
\hline \multirow{2}{*}{$\begin{array}{l}\text { Country } \\
\text { Region }\end{array}$} & \multicolumn{2}{|l|}{ North Africa } & \multicolumn{3}{|l|}{ South Africa } & \multirow{2}{*}{$\begin{array}{l}\text { West Africa } \\
\text { Nigeria [22] }\end{array}$} \\
\hline & Sudan [35] & Egypt [39] & Johannesburg [38] & Cape Town [37] & KwaZulu Natal [36] & \\
\hline Study year & 2001-2006 & 2012-2013 & 1984-2003 & 1968-2006 & 1994-2006 & 2005-2012 \\
\hline Number of children & 205 & 1018 & $153^{*}$ & 149 & 126 & 53 \\
\hline CKD definition & GFR $<50$ & CKD 1-5 & ESKD & Transplant & CKD 2-5 & CKD 5 \\
\hline \multicolumn{7}{|l|}{ Major aetiologies, $n(\%)$} \\
\hline CAKUT & $36(17.5)$ & $468(46)$ & $56(36.6)$ & $69(46)$ & $27(21.4)$ & $11(20.8)$ \\
\hline Glomerular diseases & $52(25.4)$ & $156(15.3)$ & $47(30.7)$ & $52(35)$ & $68(54)$ & $41(77.4)$ \\
\hline Hereditary nephropathy & $14(6.8)$ & $68(6.7)$ & $13(8.5)$ & $7(4.7)$ & - & - \\
\hline Urolithiasis & $19(9.3)$ & - & - & - & - & - \\
\hline Unknown & $80(39.1)$ & $210(20.6)$ & - & - & - & - \\
\hline
\end{tabular}

$C A K U T$, congenital anomalies of the kidneys and urinary tract; $C K D$, chronic kidney disease; ESKD, end-stage kidney disease; GFR, glomerular filtration rate; $* 183$ children received 283 kidney grafts; aetiologies of ESKD were presented for only 153 children 
dialysis lines are primed with blood in order to safely dialyse smaller children, which reduces the likelihood of finding a compatible kidney graft when kidney transplantation becomes necessary. The lower density of kidney health manpower for children compared with adults further worsens the disparity in kidney care in the continent. The near absence of kidney services in rural areas, where almost $50 \%$ of the population lives further accentuates the disparity [42]. For example, in Kenya, there are four centres offering paediatric haemodialysis in the capital city, one in Eldoret and none in other parts of the country. A similar finding was reported by Antwi [43] in Ghana where all the dialysis centres were situated in the southern part with none in the northern twothirds of the country. A weak referral system together with limited and unreliable transportation between the rural areas and the cities in Africa exaggerates the disparities in kidney care, especially in paediatric care, received in the continent.

Kidney transplantation (KTx) is present in 16 African countries, namely, all the countries in North Africa, Republic of South Africa and Namibia in South Africa, Kenya, Tanzania, Ethiopia, Mauritius and Seychelles in East Africa and Nigeria, Ghana and Cote D'Ivoire in West Africa [40••, $44,45]$. The median incidence of kidney transplantation in the continent is estimated at $4.6 \mathrm{pmp}$ compared with the global median of 14 [46•]. African countries with advanced KTx services, namely Republic of South Africa and the countries in North Africa, provide KTx for all age categories of children. However, in the other countries, only older children have such access. For example, a recent study in Nigeria reported that $<3 \%$ of the kidney transplants performed in Nigeria were in children and more than $40 \%$ of the children were at least 15 years at the time of transplantation [47•]. In many of the countries with no or limited KTx, it is a common practice for patients whose families could afford it to emigrate to other countries or to get the kidney transplantation done overseas; India represents the most common choice for the latter [48•, 49]. Deceased kidney transplantation is only available in Morocco, Algeria, Tunisia and South Africa [40•]; this option requires legislation around brain death and its absence in many of the countries negatively impacts the pool of kidney grafts and worsens access of children to KTx.

Diagnostic modalities for kidney disease in children in the continent have improved with widespread availability of sonography. However, modalities such as urodynamics and nuclear medicine scans are still largely unavailable. For example, in Nigeria, there is only one functioning nuclear medicine centre for the country with a population of 211 million [1,50•]. Medications for kidney diseases have become more available compared to several decades ago, largely as a result of cheaper and good-quality generics. Calcineurin inhibitors, mycophenolic acid and its derivatives, monoclonal antibodies, are now available but remain largely unaffordable to most children and are in tablets or capsule formulations that are not easy to administer to younger children.

\section{Health Manpower for Kidney Care}

Africa has the least density of health manpower in the world. The World Health Organization (WHO) in its Global Health Observatory in 2018 estimated that there were 2.1 medical doctors and 9.94 nurses and midwives per 10,000 population in SSA with North Africa faring slightly better [51•]. However, both regions are well below the global average of 17.54 medical doctors and 39.05 nurses and midwives per 10,000 population. In contrast for example, Europe has 20 times more doctors per 10,000 population than SSA. The population of medical specialists in kidney care is even worse. The global survey conducted by the International Society of Nephrology showed that in 2018, the global median number of nephrologists was 9.95 per million population and $0.6 \mathrm{pmp}$ in Africa [40••]. In a recently published textbook, Nephrology Worldwide, the authors reported that the number of nephrologists per million population ranged from 0.22 in Uganda to 2.5 in the Republic of South Africa [52•]. The picture is bleaker for children who make up $42 \%$ of the 1.1 billion population in the continent; the number of paediatric nephrologists per million population is well below 1. For example, in Lagos, Southwest Nigeria, there are only two paediatric nephrologists for the 20 million inhabitants of the state. This is a major challenge not only for clinical management but also for advocacy for children with kidney disease. Furthermore, the few kidney specialists in the continent are found in large hospitals located in urban centres. With about $50 \%$ of the continent living in rural areas, most children have no access to kidney care. This is another driver of missed diagnosis of kidney diseases in the continent.

In recent years, professional organisations such as the International Pediatric Nephrology Association (IPNA), International Society of Nephrology (ISN) and International Society of Peritoneal Dialysis (ISPD) have supported the training of manpower in paediatric nephrology in the continent by providing training grants and linking trainees with established centres, mostly in Egypt and South Africa [48, 53•, 54•]. This has resulted in over 35 paediatricians trained in nephrology from South Africa alone. For example, three of the authors (CIE, BA, RE) enjoyed training support from IPNA and ISN to undergo training in paediatric nephrology at Red Cross War Memorial Children's Hospital, Cape Town, South Africa, under two of the authors (PN, MM). In addition, the Saving Young Lives Program, a collaborative effort of these professional associations, has supported the training of teams of medical doctors and nurses in initiating and strengthening acute peritoneal dialysis services in 
several countries in Africa [55]. The COVID-19 pandemic, despite the immense negative impact on healthcare delivery, has facilitated on-line learning and attendance of virtual congresses which promotes continuing medical education. These learning opportunities were largely previously unavailable to the paediatric nephrologists in low-resource countries who could not afford the cost of travels.

However, despite the modest gain in health manpower for kidney care, like all other aspects of healthcare in the continent, migration to better resourced regions of the world remains a perennial threat. For example, $38 \%$ of the hospital doctors in the National Health Service (NHS) in England gained their medical degree outside the UK while 22 out of every 1000 NHS staff identified as Africans [56]. Furthermore, a national poll conducted in Nigeria in 2018 found that $88 \%$ of the medical doctors polled were currently seeking to work abroad with the UK, USA and Canada being the top three destinations [57]. The net migration of healthcare workers out of the continent may persist during and after the COVID-19 pandemic as more governments in OECD countries promote faster integration of migrant healthcare workers into their systems [58]. The prospect of better job satisfaction, standard of living and increased income remains potent push factors from the continent. With only $0.4 \mathrm{pmp}$ nephrology trainee reported in Africa, compared with 5.8 pmp in Western Europe, the gap in kidney care in the continent may worsen with time $[40 \bullet \bullet, 46]$. It is reassuring to note that the feeling of making a difference and helping to build resources in one's own country may counteract these push factors to some degree as the majority of paediatric nephrologists trained by IPNA and ISN have indeed returned and stayed in their countries of origin.

\section{Financing Kidney Care and Research in the Continent}

Public spending on health in the continent is among the lowest in the world. In 2018, the WHO estimated that the current health expenditure per capita in Africa was a meagre 132 US dollars [59]. Furthermore, African governments spent the least percentage of its expenditure on health at $6.69 \%$; only four African governments in 2018 spent more than $10 \%$ of its domestic expenditure on health [59]. Not surprising, only in six of the 42 African countries surveyed in 2018 by ISN was non-dialysis CKD care funded by the government and free at the point of delivery [40••]. Consequently, for most families in the continent, paying for kidney care is exorbitant, unplanned and out of pocket. In the face of high burden of neonatal morbidities and infection-related diseases such as malaria, pneumonia and diarrhoeal diseases, financing kidney care is not a priority for most African governments and multilateral donor agencies. As a result of the austere level of spending on overall health and kidney care, many children present late to care and are unable to afford essential kidney care. The meagre spending on healthcare contributes to the unavailability of many health diagnostic and therapeutic modalities in the continent. Also, the low spending on healthcare is a major driver of brain drain and a strong disincentive to those aspiring to pursue a career in paediatric nephrology and its allied specialties. Overall, these factors act in concert to worsen the care and outcome of children with kidney diseases in the continent.

Although African governments pledged in 2007 to contribute $1 \%$ of their GDP to research and development, the pledge has never been met in almost all the countries in the continent. In 2017 , for example, only an average $0.4 \%$ of the GDP of SSA was committed to R\&D [60]. Funding for research in the continent is uniquely from the public sector like the government and international agencies, unlike in the developed world where the private sector is the major donor source [61]. Major international sources of funding for health research in the continent include the National Institutes of Health (NIH), UK Medical Research Council European and Developing Countries Clinical Trials Partnership and Wellcome Trust [62]; it is not uncommon that the donors' research priorities are sometimes at variance with the continent's priorities. The low funding for research means many important research into the unique paediatric kidney diseases in the continent are not undertaken or they are funded poorly from the researchers' meagre income.

Of notable mention is the ongoing Human Heredity and Health in Africa (H3A) Kidney Disease Research Network (part of the larger H3A consortium) which is funded by the NIH to investigate the genetic and environmental underpinnings of common kidney diseases in Africans in the continent [63•]. In addition, the research efforts aim to build crucial research capacity in genomics, ethics, social implications of research, bioinformatics, biobanking, networking and academic publication. It is currently enrolling children with idiopathic childhood nephrotic syndrome and sickle cell disease in more than 10 centres in Ghana and Nigeria with centres in South Africa and Cameroon expected to join soon.

\section{The Role of Preventive Paediatric Nephrology in Africa}

Taken together, the unique features of healthcare in the continent support the primacy and cost-effectiveness of measures aimed at preventing and detecting early kidney diseases in children. The measures that may potentially have the most impact on paediatric kidney care in the continent include improving access to safe drinking water and sanitation [64], use of long-lasting insecticide-treated mosquito nets and 
prompt treatment of malaria [65], improving childhood and maternal nutrition especially just before and during pregnancy [66], increasing facility births and antenatal diagnosis of CAKUT and scaling up routine childhood immunisation and universal healthcare $[67,68]$; where universal healthcare already exists, kidney services should be included in the coverage. In Africa, the continent with the least density of paediatric kidney manpower, training of non-medical doctors and non-paediatric nephrologists to manage children with kidney diseases will have a major salutary effect on kidney outcome as it increases the pool of knowledgeable and skilful manpower and improves access to care.

\section{Conclusion}

Paediatric nephrology in Africa has its own peculiar challenges not only in terms of the unique kidney pathologies but also in terms of lack of available treatment modalities including both acute and chronic dialysis and access to transplantation for children. Advocacy for paediatric nephrology remains a priority as adults are often prioritised in the management of kidney disease. Human manpower has improved in the last two decades largely due to training input of international professional organisations. However, sustained support of paediatric nephrologists is needed to prevent them from migrating to better-resourced regions of the world. On-line education and support from training centres as well as attendance of virtual congresses has fostered continuing medical education but affordable investigations including genetic testing, equipment and facilities for paediatric dialysis and kidney transplantation remain a major challenge.

\section{Declarations}

Conflict of Interest The authors declare no competing interests.

Human and Animal Rights and Informed Consent This article is not a report involving human or animal subjects performed by any of the authors.

\section{References}

Papers of particular interest, published recently, have been highlighted as:

- Of importance

$\bullet$ Of major importance

1. United Nations Population Fund: World population dashboard. https://www.unfpa.org/data/world-population-dashboard (2021). Accessed 29th July 2021.
2. International Monetary Fund: GDP per capita, current prices. https://www.imf.org/external/datamapper/NGDPDPC@WEO/ OEMDC/ADVEC/WEOWORLD (2021). Accessed 29th July 2021.

3. The World Bank: World Bank open data. https://data.worldbank. org/ (2021). Accessed 29th July 2021.

4. Varrella S: GDP per capita of African countries 2021. https:// www.statista.com/statistics/1121014/gdp-per-capita-of-africancountries/ (2021). Accessed 29th July 2021.

5. el Ali TM, Rahman AH, Karrar ZA. Pattern and outcome of renal diseases in hospitalized children in Khartoum State. Sudan Sudan J Paediatr. 2012;12(2):52-9.

6. Antwi S. Childhood renal disorders in Ghana: a 3-year data review. Pediatr Nephrol. 2013;28(8):1416.

7. Ladapo TA, Esezobor CI, Lesi FE. Pediatric kidney diseases in an African country: prevalence, spectrum and outcome. Saudi J Kidney Dis Transpl. 2014;25(5):1110-6. https://doi.org/10. 4103/1319-2442.139976.

8. Obiagwu PN, Lugga AS, Abubakar AA. Pattern of renal diseases in children attending paediatric nephrology clinic of Aminu Kano Teaching Hospital, Kano. Niger J Clin Pract. 2019;22(7):920-5. https://doi.org/10.4103/njcp.njcp_538_18. Highlights the common paediatric kidney diseases in an hot dry region of Nigeria with low routine childhood vaccination coverage

9. Owen EP, Nandhlal J, Leisegang F, Van der Watt G, Nourse P, Gajjar P. Common mutation causes cystinosis in the majority of black South African patients. Pediatr Nephrol. 2015;30(4):595601. https://doi.org/10.1007/s00467-014-2980-7.

10. Fadel FI, Kotb MA, Abdel Mawla MA, Hasanin RM, Salem AM, Fathallah MG, et al. Primary hyperoxaluria type 1 in children: clinical classification, renal replacement therapy, and outcome in a single centre experience. Ther Apher Dial. 2021. https://doi. org/10.1111/1744-9987.13666.

11. Anwar WA, Khyatti M, Hemminki K. Consanguinity and genetic diseases in North Africa and immigrants to Europe. Eur J Public Health. 2014;24(Suppl 1):57-63. https://doi.org/10.1093/ eurpub/cku104.

12. Esezobor CI, Ladapo TA, Lesi FE. Clinical profile and hospital outcome of children with severe acute kidney injury in a developing country. J Trop Pediatr. 2015;61(1):54-60. https://doi.org/ 10.1093/tropej/fmu066.

13.• Ademola AD, Asinobi AO, Ekpe-Adewuyi E, Ayede AI, Ajayi SO, Raji YR, et al. Acute kidney injury among paediatric emergency room admissions in a tertiary hospital in South West Nigeria: a cohort study. Clin Kidney J. 2019;12(4):521-6. https:// doi.org/10.1093/ckj/sfy 120 . A recent article highlighting the frequent causes of paediatric acute kidney injury in Africa to include sepsis, primary kidney disease and malaria

14. $\bullet$ World Health Organization. World malaria report. 20 years of global progress and challenges. Geneva: World Health Organization; 2020. p. 2020. WHO in this report documented that $94 \%$ each of the cases and deaths due to malaria in 2019 occured in Africa

15. Conroy AL, Hawkes M, Elphinstone RE, Morgan C, Hermann $\mathrm{L}$, Barker KR, et al. Acute kidney injury is common in pediatric severe malaria and is associated with increased mortality. Open Forum Infect Dis. 2016;3(2):ofw046. https://doi.org/10.1093/ ofid/ofw046.

16.•• Oshomah-Bello EO, Esezobor CI, Solarin AU, Njokanma FO. Acute kidney injury in children with severe malaria is common and associated with adverse hospital outcomes. J Trop Pediatr. 2020;66(2):218-25. https://doi.org/10.1093/tropej/fmz057. This article shows that acute kidney injury is highly prevalent in children with severe malaria and underrecognised using the current WHO criteria 
17. Medani SA, Kheir AE, Mohamed MB. Acute kidney injury in asphyxiated neonates admitted to a tertiary neonatal unit in Sudan. Sudan J Paediatr. 2014;14(2):29-34.

18. Antwi S, Sarfo A, Amoah A, Appia AS, Obeng E. Acute kidney injury in children: 3-year data review from Ghana. Int J Pediatr Res. 2015;1(2).

19. Alaro D, Bashir A, Musoke R, Wanaiana L. Prevalence and outcomes of acute kidney injury in term neonates with perinatal asphyxia. Afr Health Sci. 2014;14(3):682-8. https://doi. org/10.4314/ahs.v14i3.26.

20. Olowu WA, Niang A, Osafo C, Ashuntantang G, Arogundade FA, Porter J, et al. Outcomes of acute kidney injury in children and adults in sub-Saharan Africa: a systematic review. Lancet Glob Health. 2016;4(4):e242-50. https://doi.org/10.1016/ S2214-109X(15)00322-8.

21. 2021. https://data.worldbank.org/indicator/SH.STA.BRTC.ZS. Accessed 29th July 2021.

22. Asinobi AO, Ademola AD, Ogunkunle OO, Mott SA. Paediatric end-stage renal disease in a tertiary hospital in South West Nigeria. BMC Nephrol. 2014;15:25. https://doi.org/10.1186/ 1471-2369-15-25.

23. Kéita Y, Sylla A, Moreira C, Seck A, Sall MG, Seck N. Epidemiological, clinical and developmental aspects of chronic kidney disease stages 3-5 (CRF) in children in a pediatric hospital in Senegal. Afr J Paediatr Nephrol. 2014;1(2):90-5.

24. Petersen KL, Moore DP, Kala UK. Posterior urethral valves in South African boys: Outcomes and challenges. S Afr Med J. 2018;108(8):667-70. https://doi.org/10.7196/SAMJ.2018. v108i8.12934. This article highlights the infrequent detection of CAKUT antenatally in children in Africa; less than $5 \%$ of the children had antenatal diagnosis of posterior urethral valve in this study

25. Nyagetuba M, Mugo R, Hansen E. Management of Posterior Urethral Valves in Rural Kenya. Ann Afr Surg. 2016;13(1):12-4.

26. Orumuah AJ, Oduagbon OE. Presentation, management, and outcome of posterior urethral valves in a Nigerian tertiary hospital. Afr J Paediatr Surg. 2015;12(1):18-22. https://doi.org/10. 4103/0189-6725.150937.

27. Fredrick F, Francis JM, Ruggajo PJ, Maro EE. Renal abnormalities among HIV infected children at Muhimbili National Hospital (MNH)-Dar es Salaam. Tanzania BMC Nephrol. 2016;17:30. https://doi.org/10.1186/s12882-016-0242-6.

28. Ekrikpo UE, Kengne AP, Bello AK, Effa EE, Noubiap JJ, Salako BL, et al. Chronic kidney disease in the global adult HIV-infected population: a systematic review and meta-analysis. PLoS One. 2018;13(4):e0195443. https://doi.org/10.1371/journ al.pone.0195443. The sytematic review documented the high burden of chronic kidney disease due to HIV in Africa

29. Kaze FF, Kengne AP, Atanga LC, Monny Lobe M, Menanga AP, Halle MP, et al. Kidney function, urinalysis abnormalities and correlates in equatorial Africans with sickle cell disease. Clin Kidney J. 2013;6(1):15-20. https://doi.org/10.1093/ckj/sfs100.

$30 . \bullet$ Esezobor CI, Solarin AU, Gbadegesin R. Changing epidemiology of nephrotic syndrome in Nigerian children: a crosssectional study. PLoS One. 2020;15(9):e0239300. https://doi. org/10.1371/journal.pone.0239300. The largest to date study involving over 200 Black children with idiopathic childhood nephrotic syndrome in Africa with high rate of steroid sensitivity similar to other races

31. Coulibaly PNA, Adonis koffy LY, Diarrasouba G, Niamien E, Kouassi F, Koutou E, et al. The initial response to corticosteroid therapy in childhood nephrotic syndrome in Cote D'ivoire. Afr J Paediatr Nephrol. 2014;1(2):57-61.

32. Olowu WA, Ademola A, Ajite AB, Saad YM. Childhood nephrotic syndrome in tropical Africa: then and now. Paediatr
Int Child Health. 2017;37(4):259-68. https://doi.org/10.1080/ 20469047.2017.1374002.

33. Lewandowski LB, Schanberg LE, Thielman N, Phuti A, Kalla AA, Okpechi I, et al. Severe disease presentation and poor outcomes among pediatric systemic lupus erythematosus patients in South Africa. Lupus. 2017;26(2):186-94. https://doi.org/10. $1177 / 0961203316660625$.

34. Adelowo OO, Olaosebikan BH, Animashaun BA, Akintayo RO. Juvenile systemic lupus erythematosus in Nigeria. Lupus. 2017;26(3):329-33. https://doi.org/10.1177/0961203316672927.

35. el Ali TM, Abdelraheem MB, Mohamed RM, Hassan EG, Watson AR. Chronic renal failure in Sudanese children: aetiology and outcomes. Pediatr Nephrol. 2009;24(2):349-53. https://doi. org/10.1007/s00467-008-1022-8.

36. Bhimma R, Adhikari M, Asharam K, Connolly C. The spectrum of chronic kidney disease (stages 2-5) in KwaZulu-Natal. South Africa Pediatr Nephrol. 2008;23(10):1841-6. https://doi.org/10. 1007/s00467-008-0871-5.

37. McCulloch MI, Gajjar P, Spearman CW, Burger H, Sinclair P, Savage L, et al. Overview of a paediatric renal transplant programme. S Afr Med J. 2006;96(9 Pt 2):955-9.

38. Pitcher GJ, Beale PG, Bowley DM, Hahn D, Thomson PD. Pediatric renal transplantation in a South African teaching hospital: a 20-year perspective. Pediatr Transplant. 2006;10(4):441-8. https://doi.org/10.1111/j.1399-3046.2006.00489.x.

39. Safouh H, Fadel F, Essam R, Salah A, Bekhet A. Causes of chronic kidney disease in Egyptian children. Saudi J Kidney Dis Transpl. 2015;26(4):806-9. https://doi.org/10.4103/1319-2442. 160224.

40.• Bello AK, Levin A, Lunney M, Osman MA, Ye F, Ashuntantang G, et al. Global Kidney Health Atlas: a report by the International Society of Nephrology on the global burden of end-stage kidney disease and capacity for kidney replacement therapy and conservative care acrossworld countries and regions. Brussels, Belgium: International Society of Nephrology; 2019. p. 1-164. The most comprehensive report of the burden of chronic kidney disease and kidney resources including manpower in the world published by the International Society of Nephrology

41. Esezobor CI, Ladapo TA, Lesi FE. Peritoneal dialysis for children with acute kidney injury in Lagos, Nigeria: experience with adaptations. Perit Dial Int. 2014;34(5):534-8. https://doi.org/10. 3747/pdi.2013.00097.

42. Esezobor CI, Oniyangi O, Eke F. Paediatric dialysis services in Nigeria: availability, distribution and challenges. West Afr J Med. 2012;31(3):181-5.

43. Antwi S. State of renal replacement therapy services in Ghana. Blood Purif. 2015;39(1-3):137-40. https://doi.org/10.1159/ 000368942.

44. Loua A, Feroleto M, Sougou A, Kasilo OMJ, Nikiema JB, Fuller $\mathrm{W}$, et al. A review of policies and programmes for human organ and tissue donations and transplantations, WHO African Region. Bull World Health Organ. 2020;98(6):420-5. https://doi.org/10. 2471/BLT.19.236992.

45. Min Wan DI, Fagoonee K. Global dialysis perspective: Mauritius. Kindey360. 2021. https://doi.org/10.34067/KID.00009 82021.

46.• Oguejiofor F, Kiggundu DS, Bello AK, Swanepoel CR, Ashuntantang G, Jha V, et al. International Society of Nephrology Global Kidney Health Atlas: structures, organization, and services for the management of kidney failure in Africa. Kidney Int Suppl (2011). 2021;11(2):e11-e23. https://doi.org/10.1016/j. kisu.2021.01.009. An initiative by the International Society of Nephrology to document the organisation of services for the management of kidney failure in Africa

47. Eke FU, Ladapo TA, Okpere AN, Olatise O, Anochie I, Uchenwa $\mathrm{T}$, et al. The current status of kidney transplantation in Nigerian 
children: still awaiting light at the end of the tunnel. Pediatr Nephrol. 2021;36(3):693-9. https://doi.org/10.1007/s00467-02004753-7. An article showcasing the huge disparity in kidney care between children and adults in Africa using transplantation in Nigeria as an example

48. Furia FF, Shoo J, Ruggajo PJ, Kilonzo K, Basu G, Yeates K, et al. Developing nephrology services in low income countries: a case of Tanzania. BMC Nephrol. 2019;20(1):378. https://doi. org/10.1186/s12882-019-1568-7.

49. Okafor UH. Transplant tourism among kidney transplant patients in Eastern Nigeria. BMC Nephrol. 2017;18(1):215. https://doi. org/10.1186/s12882-017-0635-1.

50. Orunmuyi AT, Lawal IO, Omofuma OO, Taiwo OJ, Sathekge MM. Underutilisation of nuclear medicine scans at a regional hospital in Nigeria: need for implementation research. Ecancermedicalscience. 2020;14:1093. https://doi.org/10.3332/ecancer. 2020.1093.

51. World Health Organization. The Global Health Observatory: SDG Target 3.c I Health workforce: Substantially increase health financing and the recruitment, development, training and retention of the health workforce in developing countries, especially in least developed countries and small island developing States. 2021. https://www.who.int/data/gho/data/themes/ topics/indicator-groups/indicator-group-details/GHO/sdg-target3.c-healthworkforce. Accessed 29 Jul 2021. A comprehensive database maintained by the World Health Organization

52. Moura-Neto JA, Carolino Divino-Filho JC, Ronco C, editors. Nephrology Worldwide (1st ed.). Switzerland: Springer Nature Switzerland; 2021. First of its kind to describe nephrology services in $\mathbf{5 1}$ countries from all regions of the world from the perspective of the local practitioners

53. Harris DC, Dupuis S, Couser WG, Feehally J. Training nephrologists from developing countries: does it have a positive impact? Kidney Int Suppl. 2012;2(3):275-8. https://doi.org/10.1038/ kisup.2012.32.

54. IPNA: Annual Report 2019. https://theipna.org/wp-content/uploa ds/2020/05/IPNA-Annual-Report-2019_Final.pdf. Accessed 13 Aug 2021.

55. Smoyer WE, Finkelstein FO, McCulloch MI, Carter M, Brusselmans A, Feehally J. "Saving Young Lives" with acute kidney injury: the challenge of acute dialysis in low-resource settings. Kidney Int. 2016;89(2):254-6. https://doi.org/10.1016/j.kint. 2015.10.009.

56. Baker C. NHS staff from overseas: statistics. NHS Digital; 2020. https://commonslibrary.parliament.uk/research-briefings/ cbp-7783/. Accessed 1 Aug 2021.

57. NOIPolls: New survey reveals 8 in 10 Nigerian doctors are seeking work opportunities abroad. https://noi-polls.com/new-survey-reveals-8-in-10-nigerian-doctors-are-seeking-work-oppor tunities-abroad/ (2018). Accessed 8th August 2021.

58. AU Labour Migration Advisory Committee (AU-LMAC). Mobility and migration of African health workers post
COVID-19. 2020. https://ethiopia.iom.int/sites/ethiopia/files/ Mobility\%20and\%20Migration\%20of\%20African $\% 20$ Health\% 20Workers\%20Post\%20COVID-19.pdf. Accessed 29 Jul 2021.

59. World health Organization. Global Health Observatory: out-ofpocket expenditure as percentage of current health expenditure (CHE) (\%). 2021. https://www.who.int/data/gho/data/themes/ topics/indicator-groups/indicator-group-details/GHO/sdg-target-3.c-health-workforce. Accessed 29 Jul 2021.

60. UIS: Global Investments in R\&D. http://uis.unesco.org/sites/ default/files/documents/fs59-global-investments-rd-2020-en. pdf (2020). Accessed 19th September 2021.

61. Simpkin V, Namubiru-Mwaura E, Clarke L, Mossialos E. Investing in health R\&D: where we are, what limits us, and how to make progress in Africa. BMJ Glob Health. 2019;4(2):e001047. https://doi.org/10.1136/bmjgh-2018-001047.

62. WORLDRePORT: https://worldreport.nih.gov/ (2020). Accessed 19th September 2021.

63. Adu D, Ojo A, Investigators HA-K. Overview of the human heredity and health in Africa Kidney Disease Research Network (H3A-KDRN). Kidney360. 2021;2(1):129-33.

64. WHO Department of Public Health Environmental and Social Determinants of Health. Preventing diarrhoea through better water, sanitation and hygiene: exposures and impacts in lowand middle-income countries. 2014. https://www.who.int/publi cations/i/item/9789241564823. Accessed 29 Jul 2021.

65. Pryce J, Richardson M, Lengeler C. Insecticide-treated nets for preventing malaria. Cochrane Database Syst Rev. 2018;11:CD000363. https://doi.org/10.1002/14651858.CD000 363.pub3.

66. Bhutta ZA, Das JK, Rizvi A, Gaffey MF, Walker N, Horton S, et al. Evidence-based interventions for improvement of maternal and child nutrition: what can be done and at what cost? Lancet. 2013;382(9890):452-77. https://doi.org/10.1016/S01406736(13)60996-4.

67. Toor J, Echeverria-Londono S, Li X, Abbas K, Carter ED, Clapham HE, et al. Lives saved with vaccination for 10 pathogens across 112 countries in a pre-COVID-19 world. Elife. 2021;10. https://doi.org/10.7554/eLife.67635.

68. Ranabhat CL, Atkinson J, Park MB, Kim CB, Jakovljevic M. The influence of Universal Health Coverage on Life Expectancy at Birth (LEAB) and Healthy Life Expectancy (HALE): a multicountry cross-sectional study. Front Pharmacol. 2018;9:960. https://doi.org/10.3389/fphar.2018.00960.

Publisher's Note Springer Nature remains neutral with regard to jurisdictional claims in published maps and institutional affiliations. 